\title{
Fostering Risk Literacy in Elementary School
}

\author{
Christoph Till \\ Department of Mathematics and Computer Science, University of Education, Ludwigsburg, Germany
}

\begin{abstract}
Risk communication in the public domain is often transmitted with an ambigous language or misleading representations of information. This causes biases in people's understanding of risks. Furthermore people's reasoning about risks is also often biased by their emotions and feelings (Gigerenzer, 2013). This correlates with people's problems in understanding statistical and numerical information. Consequently one of the main aims of educators should be to become aware of this 'Risk Illiteracy' and to improve young learners' understanding of different aspects of Risk. From the perspective of stochastics education, this means to focus on an early encounter with probabilistic issues in reallife situations of risk. Ongoing studies discovered that mathematical concepts like proportions, expected values and conditional probabilities can be taught to children through "Natural Frequencies" in hands-on activities (Gigerenzer \& Hoffrage, 1995). This work presents an intervention study in twelve classes of $4^{\text {th }}$ graders. The aim of the study was to find out whether children have probabilistic preconcepts of risk and decision making under uncertainty, and if they do, which is the good way to foster them.
\end{abstract}

Keywords: Risk, Proportions, Decision-Making, Uncertainty, Real-Life Context

\section{INTRODUCTION}

In 1995, the British Committee on Safety of Medicines reported that the ingestion of third generation contraceptive pills raises the risk of having life-threatening thromboembolism by $100 \%$ - compared to the ingestion of second generation contraceptive pills. This unclear communication in terms of the "relative risk" led to thousands of unwanted pregnancies and abortions because women overestimated the actual risk of the new pills (Gaissmaier \& Gigerenzer, 2008). The message would have been clear, if the Committee had used the "absolute risk" in form of absolute numbers: 1 out of 7000 women who took the second generation pills should fear those threatening by-effects compared to 2 out of 7000 women who took the third generation pill. The increase of $100 \%$ in this case is the increase from 1 to 2 - statistically seen a minor change. If one wants to communicate the true risk of this situation in this example, it is important to present both the numerator and denominator of the risk equation. Two things would have scaled down the scope of the catastrophe: a more transparent risk communication and a more numerate society.

\section{Risk and Uncertainty}

Risk and decision-making under uncertainty permeate many fields. Day by day global and far reaching scientific, social, environmental or political decisions have to be made. Risks and chances of nuclear energy, genetic modified crops or certain vaccinations have to 
be weighted up against each other. On a more local scale risk-related questions arise in our daily lives: 'How should I invest my money?', 'Should I do a certain medical checkup', 'Are nutritional supplements dangerous?' or 'Is it harmful to live next to a telephone pole?' Whether on the global or local scale, questions concerning risk and decisions under uncertainty have to do with value based considerations of possible hazards or benefits (Pratt, Ainley, Kent, Levinson, Yogui \& Kapadia, 2011). By definition the risk or a risky event is one associated with a strictly positive probability of a loss of resources like health, time or money (Martignon \& Krauss, 2009). Risk can be described as a function of two variables namely the likelihood of occurrence of a hazard and the impact that the hazard may cause on an individual or a group involved should it occur (Campbell, 2007). The two variables 'likelihood' and 'impact' can be seen as two dimensions which have to be integrated in a decision process. Yet it proves more difficult than it sounds, as the magnitude of the hazard or impact may not be foreseeable and the likelihood estimations may run into difficulties when information is limited.

\section{Reasons for the Biased Perception of Risk}

Information in form of data is a good basis for a reflected decision process. Especially in medical issues looking at health statistics (of i.e. chances of recovery with certain medical interventions) can ease difficult decisions. Looking at what happened yesterday can help to get a feeling what will happen tomorrow. Experience and research shows that people tend to neither look at the data, nor do they always understand them when they look at them. There are several reasons, why people struggle with correctly estimating risk-related situations.

\section{The influence of culture, friends and the environment}

Informed decision making in risk-related situations is impeded by the fact that most impacts and their associated consequences seem to be emotionally loaded (Pratt et al., 2011). Whether an impact is judged as high or low often depends on subjective criteria. These subjective criteria are influenced by past experiences, family, friends or cultural beliefs (Spiegelhalter, Pearson \& Short, 2011). Therefore we often "fear what others fear" and act emotionally. Related to this are psychological mechanisms and an evolutional heritage that influence or even hamper good decision making (Gigerenzer, 2013). As a consequence individuals do not minimize total risk in everyday decision-making (Pratt et al., 2011). People tend to overestimate low risks like the swine influenza or vaccination but underestimate threatening risks like obesity, smoking or a computer tomography. This skewed risk perception leads to the fear of plane crushes, although planes are the safest vehicles (Gigerenzer, 2013).

\section{Communication of risk}

Informed decision making is based on data. Data can be presented in various ways: pictures, numbers, charts, graphs or language. Since risk-related data may be emotionally loaded, it is convenient to use representation formats that are objective, unbiased and easy to grasp for a wider public. Especially for lay audiences probabilities and numbers are a big challenge and this is why they should be exchanged or supported by graphical visualizations (Brase, 2008; Gresh, Deleris \& Gasparini, 2012; Spiegelhalter et al., 2011). Findings of cognitive psychologists reveal evidence that the format of representation is crucial for understanding the real harm or chance of different options in situations of uncertainty. Frequency formats are much better processed by the human mind than ratios, decimals or percentages (Brase, 2008; Gigerenzer, 2013; Gigerenzer \& Hoffrage, 1995; Spiegelhalter et al., 2011; Schapira, Nattinger \& McHorney, 2001). One reason for this may lie in the fact that frequency formats reduce the cognitive load in computing the 
probabilities (Gresh et al., 2012). Graphical and analog representations in form of icon arrays support the comprehension of numerical information. This type of representations should be more leveraged in risk communication (Brase, 2008; Gaissmaier \& Gigerenzer, 2008; Gresh et al., 2012; Gigerenzer \& Hoffrage, 1995; Schapira et al., 2001). Icon arrays use icons for each individual in a population with a certain attribute. This one-to-one match between individuals and icons invites to identification as it is directly seen as part of the whole population (Martignon \& Kurz-Milcke, 2006). Frequency formats in combination with graphical visualizations in form of icon arrays can help to understand statistical information. Those representation formats serve well for communicating statistical information as they can do part of the computation (Zhu \& Gigerenzer, 2004).

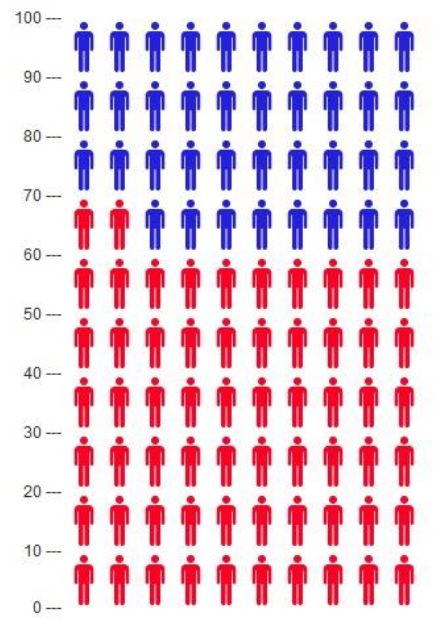

Figure 1. Icon array: A representation format which is easy to grasp

\section{Innumeracy and statistical illiteracy}

As was mentioned above statistical information about risk is communicated by means of mathematical formats like ratios, fractions, percentages or decimals. Findings reveal difficulties of people in correctly reading and interpreting these formats (Gigerenzer, 2013; Gresh et al., 2012). Even replacing percentages by frequency formats does not always help people understanding statistical information. ' 1 out of 1000' is sometimes seen as a larger ratio than ' 1 out of 10' (Galesic \& Garcia-Retamero, 2010). Nevertheless difficulties in correctly interpreting simple numerical tasks do not constitute the only problem. Findings of cognitive psychology and investigations of people's probabilistic thinking during the last 40 years reveal a flurry of cognitive illusions as well as probabilistic and statistical misconceptions (Kahnemann \& Tversky, 1979; Batanero, Godino, Vallecillos, Green \& Holmes, 1994; Garfield \& Ahlgren, 1988; Kapadia, 2009).

\section{What should be done (at school)?}

In order to advance informed decision making, the emphasis should lie on a more transparent and intuitive communication of risk in public (Gigerenzer, 2013; Spiegelhalter et al., 2011). Even more important is to prepare young learners for the risks and uncertainties they already face and they will face their whole life. They should "[...] comprehend and deal with uncertainty, variability, and statistical information in the world around them, and participate effectively in an information-laden society." (Gal \& Garfield, 1997). After they have finished their encounter with stochastics at school, students should have acquired competencies like "[...] the ability to access, use, interpret, and communicate 
probability-related information and ideas, in order to engage and effectively manage the demands of real-world roles and tasks involving uncertainty and risk" (Gal, 2012). This definition of "probability literacy" stresses out the importance of understanding uncertainty and risk. I use this definition although I will speak of "Risk Literacy" for the sake of emphasizing "Risk". De Haan, Kamp, Lerch, Martignon, Müller-Christ \& Nutzinger (2008) have formulated a list of competencies including general mathematical, probabilistic and statistical aspects that can or should be acquired at school:

- dealing with complex information: recognizing and trading-off risk, danger and uncertainty

- analyzing and judging about risks and dangers

- doing stochastic operations in risk-related real-life contexts; these considerations should be linked to equity and sustainable statements

- weighing up and discussing risks in risk-benefit and dilemma situations

- using heuristics for formulating adequate statements and gaining insights from that process, in order to plan the next actions

Based on the list of De Haan et al. (2008) the general focus lies on fostering competencies like reckoning with risk, modelling decisions in uncertain situations and interpreting graphs, numbers and frequencies in risk-related contexts by using mathematical tools. In most countries elements of probabilistic thinking are taught in primary and secondary school. In early primary grades, most of the educators are satisfied with a playful encounter of their pupils with probabilistic and statistical issues. These can be simple random experiments with urns, dies, spinners or simple statistical representations. This is a good way to introduce informal stochastic issues but remains at a tentative level. School- and graduate students often do not see the connections between randomness and real-life where uncertainty, variability and above all, risk are omnipresent. Kapadia (2009) writes:

"(...) Hence the content of the current [stochastic] curriculum [of primary school] is relatively brief. It does give an overview but lacks important detail. Perhaps the most important omission is any reference to risk and hence to real-life applications. It is certainly true that the majority of teachers would make links to real-life situations, indeed they often occur in text-books. But the lack of reference to risk is very important in the context of the current world."

\section{Risk Literacy - Which Mathematical Concepts are Important?}

Preliminary explorative studies propose a 'tool box for decision-making and reckoning with risk' (Martignon \& Krauss, 2009). They analyze mathematical competencies like proportional reasoning, dealing with expected values and understanding conditional probabilities (Kurz-Milcke et al., 2008; Martignon \& Krauss, 2009). It is my view that this bundle of competencies, including the ability to distinguish between relative and absolute risk, provides excellent ways for modelling decisions under uncertainty.

Proportional Reasoning is not only a fundamental competency in science but also a crucial prerequisite for probabilistic reasoning and therefore for the notion of risk (Martignon \& Krauss, 2009). In terms of risk, the probability of an event is often expressed as a ratio between two quantities. We only get a sense for risk magnitudes when taking into account both dimensions. Otherwise we might argue that ' 7 ill people out of 10 ' is less than '10 ill people out of 100' because 7 is less than 10 .

The expected value as the (sum of) product(s) of a value and its (their) associated likelihood(s) and the definition of risk underlie the same basic concept: outcomes are weighted with their probabilities. In the context of risk, the 'value' is a quantified resource like time, health or money. It follows that pondering between different options means comparing their 'expected values'.

Conditional probabilities are reflected in many risky scenarios: The magnitude of risk in real-life always depends on certain conditions. The risk of infection of a certain disease depends on the area where people live, the health situation of individuals, medical conditions and the base rate of the disease. All these situations can usually be described quantitatively in terms of conditional probabilities. Conditional probabilities and Bayesian 
Reasoning are also fundamental concepts for understanding test diagnostics (Gigerenzer \& Hoffrage, 1995). Given a positive test result, what is the actual likelihood that the patient is ill? Not only laypersons but also experts are often biased when making such kinds of judgments (Eddy, 1982; Gigerenzer \& Gray, 2011).

Relative and absolute risks are often misunderstood not just by lay people. It turns out that there exists a huge ambiguity concerning the meaning of these technical terms and the associated percentages (Gigerenzer, 2013). The use of relative and absolute formats are often knowingly utilized to mislead the consumer or the patient (Galesic \& GarciaRetamero, 2010). People ought to know that without taking into account the reference group, risk reductions and -increases cannot be interpreted correctly (see above).

\section{Previous Research on the Understanding of Risk of Young Children}

Preliminary studies have investigated how competencies like understanding proportional reasoning, dealing with expected values and understanding conditional probabilities can be conveyed to primary school children (Latten, Martignon, Monti \& Multmeier, 2011; Martignon \& Krauss, 2009). Fourth graders in Germany are not yet familiar with ratios and fractions; thus probabilities have to be translated into proportions and expressed in terms of frequency formats like: ' 2 out of 6'. These very intuitive numerical representations can be supported by concrete, hands-on materials, for instance colored tinkercubes. Martignon and Krauss (2009) discussed a class experiment in which they introduced a 'tool box for decision making and reckoning with risk' with 10-year-olds. The tool-box consisted of playbased activities devised to make young students aware of the characteristics of uncertainty. Contents of the tool-box were tasks in elementary Bayesian Reasoning, comparing proportions and discussing the risks and chances of different strategies in the game 'Ludo'. The authors describe this playful, heuristic and informal encounter with probabilistic phenomena as a solid basis for the formal calculus of probability in higher grades (Martignon \& Krauss, 2009). Nevertheless, this study lacked empirical consistency and statistical significance. The authors did not work with a control group, they did not compare children's performance before and after their activities and they did not test the sustainability of these activities. The presented ideas and games with children are inspiring and they motivate a well-calibrated school intervention.

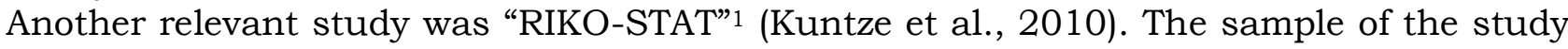
consisted of students from grade 4 (elementary school) grade 9 (middle school) as well as students from university. The focus of the study was on the evaluation of students' competencies concerning presentation, interpretation and communication of statistical information. Part of the item pool referred to risk-related questions about conditional probabilities, proportions and decision-making in risk-benefit trade-off situations. One finding of this study was that $4^{\text {th }}$ graders already have intuitions and informal stochastic pre-knowledge about risk which show a moderate increase with age: the difference between the youngest and the oldest students in the sample was though not large. This study also motivates my school intervention: in fact, some of the tasks in my tests have been extracted from RIKO-STAT.

\section{Focus of My Research}

The aim of my research was to go beyond the described studies by gathering empirical evidence on the primary intuitions of probabilistic issues in the context of risk that students aged 8 to 10 exhibit. I wanted to show, namely, that these intuitions empower children to answer questions about risk in probabilistic tasks. At the same time I wanted to show that these intuitions can be fostered and strengthened through an intervention. My

\footnotetext{
${ }^{1}$ Risiken verstehen und kommunizieren - Kompetenzen im Bereich von Statistical Literacy und ihre Förderung
} 
intervention was instructional and it aimed at fostering secondary intuitions in the sense of Fischbein (1970). Thus, two questions guided my research:

1. Which primary intuitions do children aged 8 to 10 have about pre-concepts of probability and decision making under uncertainty before they attend a corresponding learning unit?

2. Is it possible by means of a well-designed intervention to foster these intuitions and pre-concepts so that children develop early competencies in risk understanding?

\section{METHOD}

\section{Sample}

The study comprised 244 students of grade 4 aged from 8 to $12(\mathrm{M}=9.5, \mathrm{SD}=.612)$. They were students of 6 different schools in Ludwigsburg and its environs, in the state of Baden-Württemberg in southern Germany. The 131 girls and 113 boys came from twelve classes. For all of them it was the last year of primary school. The enquiry period reached from December 2012 to July 2013. Before the intervention started, the students had not been taught the contents of the learning unit. They had a minimum knowledge of probability and statistics corresponding to what is recommended by the German math standards of primary school. ${ }^{2}$ Nevertheless, as I think, many of the probabilistic intuitions children have stem from their extra-curricular experiences. The acquisition of classes was handled on the phone and information sheets on the procedure of the study were sent via E-mail. For the participating students, declarations of statements were submitted. There was no random assignment to treatment and control classes due to pragmatic reasons: some teachers wanted their classes to be part of the treatment whereas some teachers wanted their classes only to serve as control classes. However, this did not pose any problem as the mean pretest score for treatment and control classes did not differ significantly from each other. Due to the large sample size I had strong effect sizes and good power $\left(\mathrm{R}^{2}=.583, \mathrm{~F}_{222}=2.646, \mathrm{f}^{2}=1.398,1-\beta=1.00\right)$.

\section{The Intervention}

The intervention in form of a learning unit consisted of four single math lessons. In each lesson the students worked with hands-on material in form of colored tinker-cubes. The cubes served as tool for describing proportions. These proportions were then presented most of the time in form of icon arrays. This mix of enactive and iconic representations of information should ensure that students grasp the concept "proportions" intuitively through visual perception (without the use of numeric representations, Scholz \& Waschescio, 1986).
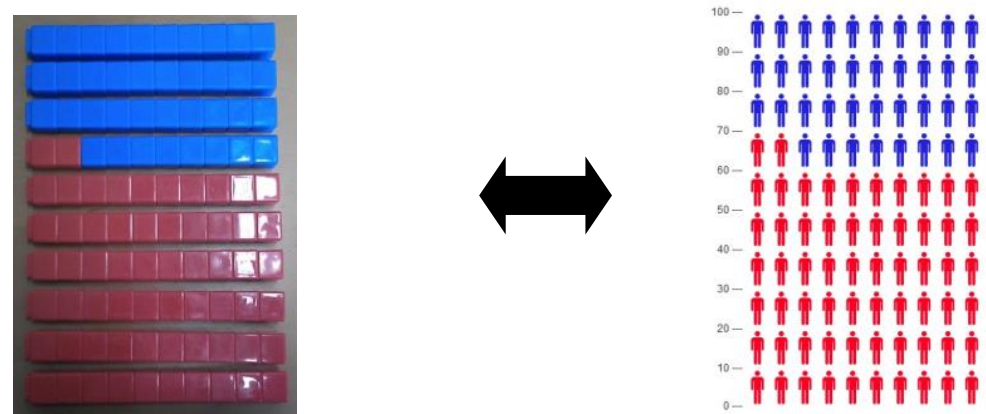

Figure 2. Representation of ' $62 \%$ ': with tinker-cubes and with an icon array

\footnotetext{
${ }^{2}$ http://www.kmk.org/fileadmin/veroeffentlichungen beschluesse/2004/2004_10_15-Bildungsstandards-Mathe-Primar.pdf [26.02.2014]
} 
Urns with cubes inside were shaken by the children and thus became random generators. The teaching method consisted of a mix of classroom discussion and work in groups. The students often had to make assumptions and give statements about different stochastic problems like: "What do you expect will happen?", "Which option would you choose and why?" or "Which option is the 'riskier' one?" Those assumptions were then tested empirically, by conducting experiments, and finally reflected and discussed. This approach ensured that students made intuitive and informal judgments. A given outcome then confirmed or refuted the assumptions about the probabilistic situation.

Lesson One. The first lesson covered comparisons of simple proportions in risk-related contexts. The aim was to confront the students with proportions and directly embed this first encounter in a probabilistic context. Instead of a formal comparison of fractions students compared only simple proportions and argued in an informal manner. "Person A has three pens. Two of them work and the third is broken. Person B has four pens, two of which are broken. Which person takes better care of her or his pens?"

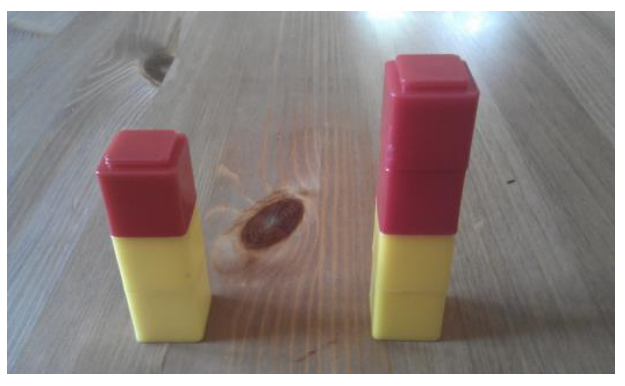

Figure 3. Informal comparison of proportions: 2 out of 3 is more than 2 out of 4

Different examples were discussed. I decided to begin with easy tasks in which either the "winning/healthy/good" colour (yellow or green cubes) or the "loosing/ill/bad" colour (red) was equal in both samples. The more difficult tasks were those in which the proportion of colours was the same (2 out of 4 compared to 5 out of 10). The most difficult tasks were those in which the proportions in each sample were different ( 1 out of 3 compared to 2 out of 10). After these comparisons different kinds of random experiments were done. I wanted the students to test empirically whether the higher proportion goes along with a higher probability. Therefore different samples were tested against each other by extracting blindly ten times from an urn. The results were noted on the board by means of a tally. Through this process the students experienced the connection between proportion and probability. A high proportion of one colour in a certain sample led to higher frequencies of this colour in that sample. They also realized that variability plays a role; for instance, a tinker-tower consisting of one yellow and one red cube at the beginning does not imply that after ten extractions one will have five red and five yellow marks in the tally. Children were helped by their visual perception when having to compare proportions expressed by tinker-towers.

Lesson Two. During the following lesson students were confronted with a trade-off situation in which they had to weigh up two different options. One option was associated with a small but certain gain and one with an uncertain high gain. The small certain gain consisted of one candy bar. The uncertain high gain consisted of four candy bars. In case they chose the risky alternative they used a random generator consisting of an urn with a red and a yellow cube. Yellow was the winning colour. 

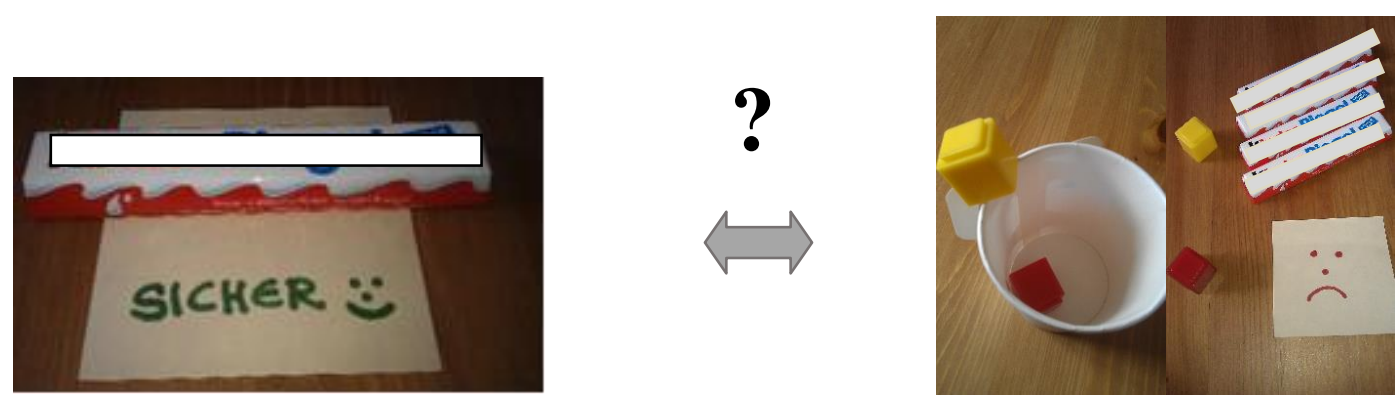

Figure 4. Trade-Off situation: Certain low win or uncertain high win?

After a discussion on the different alternatives, the students sat together in pairs and simulated the risky situation by running the random experiment ten times. On a working sheet they had to write about the comparison between the gains obtained repeating the random experiment ten times and gains obtained in the certain situation. At the end of the lesson the results of the different pairs were collected and compared. Finally, all students realized that the riskier option of this trade-off situation is associated with the higher gain on average. Yet, a few of the children maintained their opinion, to stay with the certain option rather than go for the risky one.

Lesson Three. The third lesson purported questions about relative and absolute risk reduction. We first talked about the "risk" that somebody gets hurt or the risk that something gets broken; by means of comparisons with tinkercubes I led the students to argue about "risky scenarios", noting that these are often communicated by means of proportions and ratios. "I have five frisbees. Two out of these five frisbees get lost. Imagine, I have $(10 ; 15 ; 20)$ frisbees, how many will get lost?" 3 The students also learned that proportions or ratios can become higher or smaller when the situation changes: "I now have (10; 15; 20) but I am much more careful with my frisbees. The risk that one of them gets lost is half of what it was before. How many of the $(10 ; 15 ; 20)$ frisbees will now get lost?" There was a lively discussion and other examples were described; the coloured tinkercubes served as visualization. The students received a worksheet on which they did tasks of this kind; they also had to invent and draw a situation in which a certain risk (in form of a ratio or proportion) changed with a new situation.

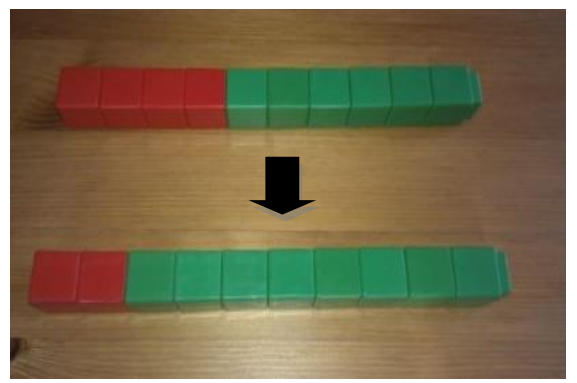

Figure 5. "The risk that children fail a test is reduced from $\underline{4 \text { out of } 10}$ to $\underline{2 \text { out of } 10}$ if they all learn a lot."

Lesson Four. The fourth and last lesson comprised questions about conditional probabilities and Bayesian Reasoning which were simulated and modelled by and with the children. At first the students discussed about how individuals differ from each other having different features. Those features were then encoded by the use of tinkercubes which could be plugged together. The cubes represented the students' features; red and blue cubes stood for a certain feature, for example for girls and boys. Another feature, like long hair and short hair was then coded with yellow and green cubes, which were plugged to

\footnotetext{
${ }^{3}$ In this case I am aware that the possible answers should present variability and randomness. Yet I was expecting the exact generalized proportions from the example, namely $4,6,8$.
} 
the blue and red ones. We then talked about the proportions of individuals and how the proportions change when new features are considered. "There are 8 boys (blue cubes) and 2 girls (red cubes). Some of children have short hair (green cubes) and some have long hair (yellow). You see someone with long hair (yellow). Is it a girl?"

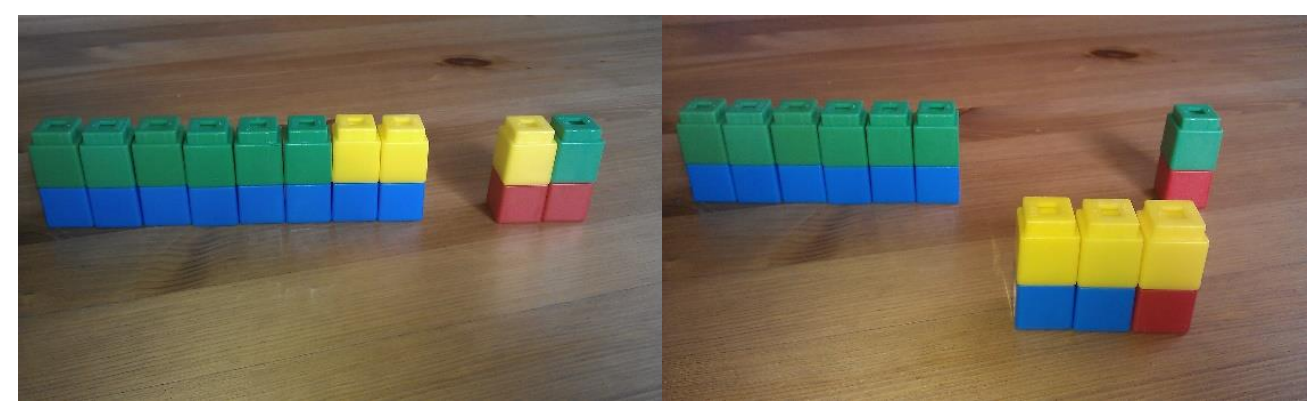

Figure 6. Elementary Bayesian Reasoning: boys (blue) and girls (red) with short hair (green) and long hair (yellow)

Students worked not only with the tinkercubes, they simulated the situation themselves: Ten of them whose features corresponded to the example, came to the blackboard and represented the situation. This way they recognized that the question above reduced the range considered from ten to three. They understood that the proportion which was relevant for the question was 1 out of 3 . On a working sheet they reported what they had done and illustrated the situation in several steps ("How many boys/girls are there at the beginning?", "Which of them have long/short hair?", "How many of those with long hair are girls?").

Afterwards, a transfer of these insights took place with other situations and the same materials.

\section{Instrument}

I conducted a pretest, a posttest and a follow-up test in each of the twelve classes. I constructed a new test instrument based on discussions with my advisor, teachers and math educators in Ludwigsburg and psychologists of the Max Planck Institute in Berlin. The test includes different tasks on elementary comparisons of probabilities, proportions and frequencies, expected values, simple sample distributions, conditional proportions as well as one task on risk reduction. The items consist partly of open questions where students have to formulate their answers to stochastic text problems. The rest of the items consist of closed tasks where the students have to mark the right answers with a cross or cross the right amount of certain objects. The tests have the internal consistency of a pretest $=.72, \mathrm{a}_{\text {posttest }}=.82$ and $\mathrm{a}$ follow-up test $=.81$.

In my study each of the tests took the students about thirty minutes. The items of the pre- post- and the follow-up test are equivalent as far as subject-specific contents and requirements are concerned; the structure, the order and cover stories of the items were different. This ensured that students did not perform better just by remembering what they had previously done. Each test sheet was coded. Information about the students' grades in Mathematics and German of the last school year and gender was collected anonymously.

\section{Experimental Design}

The intervention study should shed light on children's probabilistic intuitions which are useful in the context of risk. The experimental design investigated whether a specific training of competencies in risk literacy caused treatment classes to outperform the control classes significantly. Thus the sample was divided into a treatment group (8 treatment 
classes) and a baseline control group (4 classes). Before the intervention in form of a learning unit started, I conducted the pretest in each of the twelve classes in order to get information about foreknowledge about the contents to be trained. The treatment classes were taught about different contents during one week, while the control classes attended their regular math classes. One week after the pretest, all students had to do the posttest. After three months, I conducted a follow-up test in each of the twelve classes in order to get information about sustainable learning effects.

\section{Data Analysis}

A multiple regression analysis was conducted. The aim was to predict the posttest (follow-up test) performance for each student. Hence the affiliation to the treatment group or the control group was dummy-coded and served also as predictor for the criterion posttest score (follow-up test score). The independent variables 'age', 'gender', 'pretest score', 'grade in mathematics, 'grade in German' and 'test condition' were entered in the regression. ${ }^{4}$ For the performances in the pretest and the follow-up test the variances were equal for students from the treatment and the control group, $F_{\text {pretest }}(1,206)=.005$, ns and $\mathrm{F}_{\text {follow-up test }}(1,206)=1.734$, ns. The variances of grades in maths were also equal in both groups, $\mathrm{F}_{\text {grades in mathematics }}(1,206)=.003$, ns. Nevertheless, the variances for posttest scores were significantly different in the two groups, $\mathrm{F}_{\text {posttest }}(1,206)=4.585, \mathrm{p}<.05$. Hartley's test for $\mathrm{F}_{\text {Max }}=1.105<3$.

The evaluation of assumptions showed that there were very few outliers and these had no impact on the regression (Mahalanobis Distance Max $=10.4$; Cook Distance Max $=.034$ ). The pre-analysis showed no multicollinearity (Regression 1 pretest $\rightarrow$ posttest: VIF Max $=$ 1.351; Regression 2 pretest $\rightarrow$ follow-up test: VIF Max $=1.4$ ). Residuals of the prediction were homoscedastic. Cases with missing data were valued with zero points (student did not know the answer of an item).

\section{FINDINGS}

The assumption that students aged $8-10$ have primary probabilistic intuitions has been corroborated by my experiment, because students in my sample were able to achieve about half of the total score of the pretest (50.9\%). Expectedly students from treatment and control classes achieved similar results on average. The descriptive statistics of the pretest performances reveal that almost all students had intuitions concerning simple comparisons of probabilities. Students showed also basic intuitions for conditional probabilities and very simple expected values. Despite general good intuitions (Figure 7), they had difficulties with less elementary tasks (Figure 8).

Cross the box which is more convenient if you want a black marble?

Two crosses means they are equally convenient

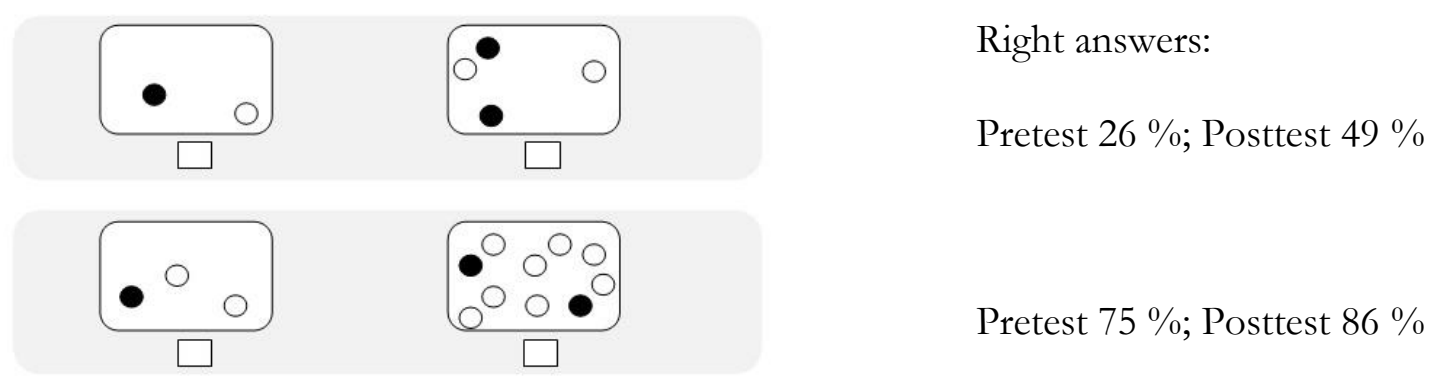

Figure 7. Simple comparisons of proportions

\footnotetext{
${ }^{4}$ I chose 'forced entry' for the regression analysis because I did not make any assumptions in which order the variables have been entered.
} 
- In garden A:

10 out 30 plants have been eaten by snails.

- In garden B:

20 out of 100 plants have been eaten by snails. $\odot$

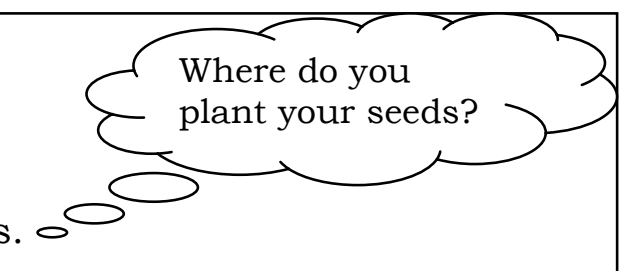

Right answers: Pretest $43 \%$; Posttest $70 \%$

Figure 8. More difficult comparisons of proportions

As conjectured, the intervention strengthened students' intuitions and fostered elementary competencies for risk assessment and probabilistic decision making. After the intervention students from the treatment classes answered $76.6 \%$ of the tasks correctly, compared to only $61.1 \%$ of the control classes. The follow-up test showed that the treatment classes achieved an average score of $66.1 \%$, while the control classes only achieved $55.9 \%$.

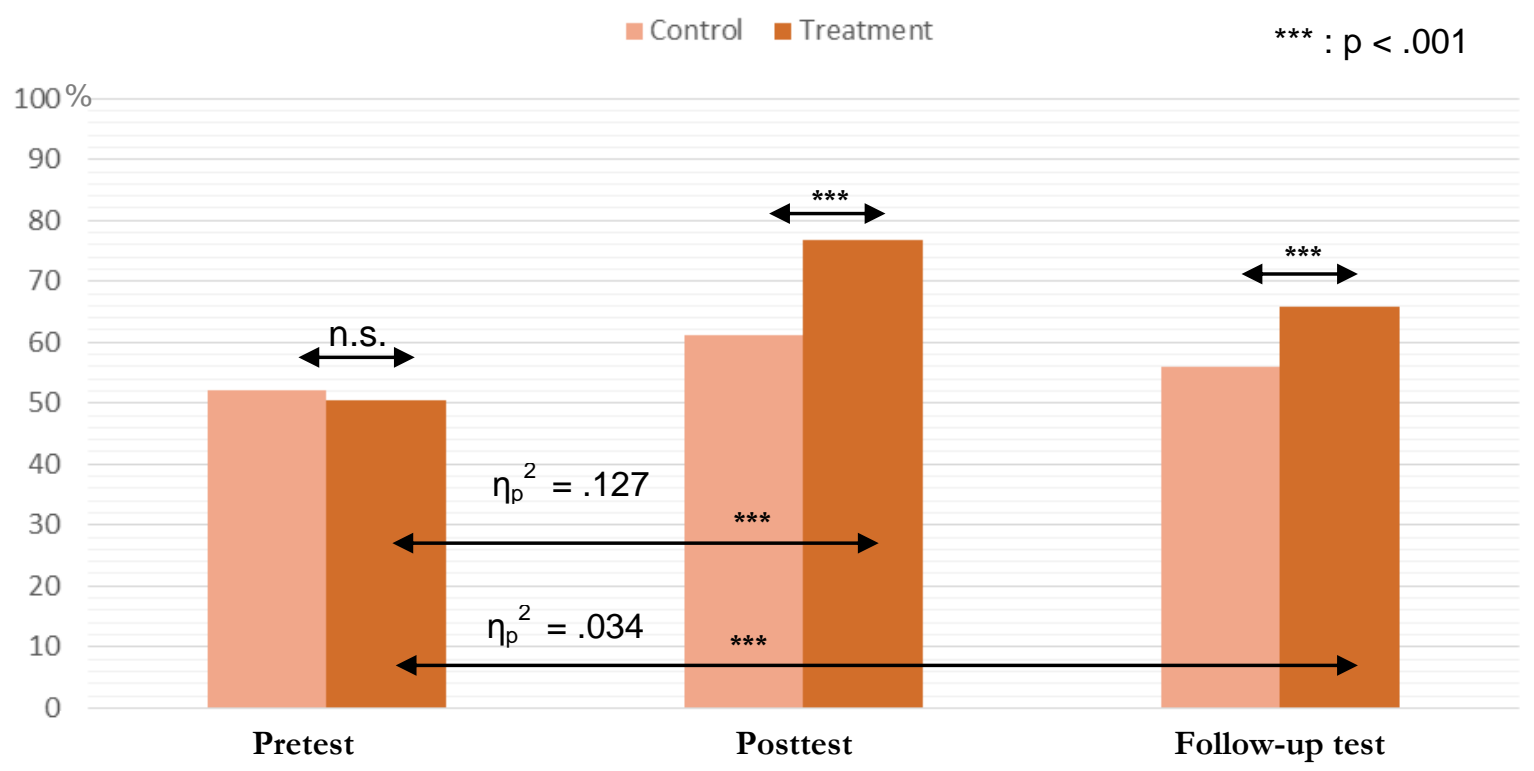

Figure 9.

The results of the multiple regression analysis (Table 1) confirmed the effectiveness of the intervention. The adjusted $\mathrm{R}^{2}$ of .577 indicates that more than $57 \%$ of the variability of the posttest performance can be predicted by the three variables 'grades in mathematics', 'pretest score' and 'test condition'.

Table 1. Predicting the posttest results

\begin{tabular}{llrcc}
\hline & Predictor & $\boldsymbol{B}$ & $\boldsymbol{S E} \boldsymbol{B}$ & $\beta$ \\
Step 1 & Pretest score & .560 & .075 & $.453^{*}$ \\
& Grade in Mathematics & -1.467 & .325 & $-.273^{*}$ \\
& & & & \\
Step 2 & Pretest score & .597 & .063 & $.483^{*}$ \\
& Grade in Mathematics & -1.514 & .273 & $-.281^{*}$ \\
& Test condition & 4.410 & .456 & $.424^{*}$ \\
\hline Note: & $\mathrm{R}^{2}=.399$ for Step 1, & $\Delta \mathrm{R}^{2}=.178$ for Step 2 $(\mathrm{p}<.001) . * \mathrm{p}<.001$. & &
\end{tabular}

The $\beta$ coefficients of these variables were significant and therefore good predictors for the performance of the posttest. The variables 'age' and 'gender' had no significant $\beta$ 
coefficients. Two models were calculated in order to outline the additional clarification of variance due to the further predictor 'test condition'. The table shows that being part of the treatment ('test condition') explains about $18 \%$ of the variance of the posttest results. A multiple regression analysis was also carried out for the prediction of the follow-up test results.

Table 2. Predicting the follow-up test results

\begin{tabular}{|c|c|c|c|c|}
\hline & Predictor & $B$ & $S E B$ & $B$ \\
\hline \multirow[t]{2}{*}{ Step 1} & Pretest score & .492 & .079 & $.393^{*}$ \\
\hline & Grade in Mathematics & -1.624 & .335 & $-.307^{*}$ \\
\hline \multirow[t]{3}{*}{ Step 2} & Pretest score & .509 & .074 & $.407 *$ \\
\hline & Grade in Mathematics & -1.682 & .311 & $-.318^{*}$ \\
\hline & Test condition & 3.116 & .521 & $.299 *$ \\
\hline
\end{tabular}

Note: $\mathrm{R} 2=.378$ for Step $1, \quad \Delta \mathrm{R} 2=.089$ for Step $2(p<.001) .{ }^{*} p<.001$.

It turned out that the same variables showed significant $\beta$ coefficients. The adjusted $R^{2}$ of .459 indicates that more than $45 \%$ of the variability of the follow-up test performance can be predicted by the variables 'grades in mathematics', 'pretest score' and 'test condition'. The results indicate that there are long-term effects of the intervention, as the significant $\beta$ coefficient 'test condition' explains about $9 \%$ of the variance of the follow-up test results. Thus, these results show that three months after the intervention students in the treatment group achieved significantly better follow-up test scores than students in the control group.

\section{DISCUSSION}

This study shows that Risk and decision making under uncertainty can be a prevailing, exciting and meaningful topic at the end of primary school with sustainable effects. It shows that it is possible to foster elementary competencies for risk assessment and probabilistic decision making in fourth class. The leitmotif of the study were representations by means of natural frequencies and icon arrays with hands-on materials in a playful learning environment, as advised by results of cognitive psychologists. With these representations children can think probabilistically without the need of fractions or percentages. The results of the pretest showed that students aged 8 to 10 have good probabilistic intuitions and the effectiveness of the intervention indicated that the students can develop secondary intuitions (Fischbein, 1970). The briefness of the intervention -4 lessons - proves that fostering that bundle of competencies for reckoning with risk and uncertainty can be achieved without causing essential changes in the mathematical curriculum. Thus, such an intervention might easily become part of the curriculum in fourth grade. Current ways of teaching data and chance in elementary school classes are often reduced to some descriptive statistics ("Which is your favorite animal?") or gambling situations with dice and spinners. Relating these learning approaches to Risk und decisionmaking under uncertainty would mean embedding them into a real-life context.

As Gigerenzer $(2011$; 2013) has repeatedly pointed out elementary probability concepts should be taught in an informal and heuristic manner at an early stage. This can help children become prepared for the uncertainties of the modern technological world where the understanding of statistical information becomes more and more indispensable. The students I investigated had much fun performing random experiments, predicting, reflecting and discussing risk-related situations. 


\section{Acknowledgements}

The author is a member of the "Cooperative Research Training Group" of the University of Education, Ludwigsburg, and the University of Tübingen, which is supported by the Ministry of Science, Research and the Arts in Baden-Württemberg. Correspondence concerning this article should be addressed to Christoph Till, Department of Mathematics and Computer Science, University of Education, Ludwigsburg, L 71634. E-mail: Till@phludwigsburg.de

\section{REFERENCES}

Batanero, C., Godino, J. D., Vallecillos, A., Green, D.R., \& Holmes, P. (1994). Errors and Ddifficulties in Understanding Elementary Statistical Concepts. International Journal of Mathematics Education in Science and Technology, 25(4), 527-547.

Brase, G. L. (2008). Pictorial Representations in Statistical Reasoning. Appl. Cognit. Psychol. DOI: $\quad$ 10.1002/acp. 1460

Retrieved from: http://www.kstate.edu/psych/research/documents / 200 9ACP.pdf

Campbell, S. (2007). What is the definition of risk? Personal communication relating to an article submitted to Journal of Risk Research.

De Haan, G., Kamp, G., Lerch, A., Martignon, L., Müller-Christ, G., Nutzinger, H. (2008). Nachhal- tigkeit und Gerechtigkeit. New York: Springer-Verlag.

Eddy, D. M. (1982). Probabilistic reasoning in clinical medicine: Problems and Opportunities. In Kahneman, D., Slovic, P., Tversky, A. (Eds.), Judgment under Uncertainty: Heuristics and Biases (pp. 249267). Cambridge: Cambridge University Press.

Fischbein, E., Pampu, I. \& Minzat, I. (1970b). Effects of age and instruction on combinatory ability in children. British Journal of Educational Psychology, 40, 261270 .

Gaissmaier, W. \& Gigerenzer, G. (2008). Statistical illiteracy undermines informed shared decision making. ZEFQ, 102, 411413.

Gal, I. (2012). Developing probability literacy: Needs and pressures stemming from frameworks of adult competencies and mathematics curricula. 12th International Congress on Mathematical Education. $1-7$.

Gal, I., Garfield J. G. (1997). Curricular goals and assessment challenges in statistics education. In Gal, I., Garfield J. G. (Eds.), The Assessment Challenge in Statistics Education (pp. 1-13). IOS press.

Galesic, M., Garcia-Retamero, R. (2010). Statistical Numeracy for Health. A Crosscultural Comparison with Probabilistic National Samples. Arch Intern Med., 170(5), 462-465. Retrieved from:

http: / / archinte.jamanetwork.com/article .aspx?articleid=415709\#RESULTS

Garfield, J. \& Ahlgren, A. (1988). Difficulties in Learning Basic Concepts in Probability and Statistics: Implications for Research. Journal for Research in Mathematics Education, 19(1), 44-63.

Gigerenzer, G. (2013). Risiko. Wie man die richtigen Entscheidungen trifft. München: Bertelsmann Verlag.

Gigerenzer, G. \& Gray, M. (2011). Better Patients. Better Doctors. Better Decisions. Envisioning Health Care 2020. Cambridge: MIT Press.

Gigerenzer, G. \& Hoffrage, U. (1995). How to improve Bayesian reasoning without instruction: Frequency formats. Psychological Review, 102(4), 684-704.

Gresh, D., Deleris, L. A., \& Gasparini, L. (2012).Visualizing Risk. IBM research report.

Kahneman, D. \& Tversky, A. (1979). Prospect Theory: An analysis of decision under risk. Economet- rica, (47), 263-291.

Kapadia, R. (2009). Chance Encounters - 20 years later. Fundamental ideas in teaching probability at school level. International Electronic Journal of Mathematics Education, 4(3), 371-386.

Kuntze, S., Gundlach, M., Engel, J. \& Martignon, L. (2010). Aspects of statistical literacy between competency measures and indicators for conceptual knowledge empirical research in the

"RIKO-STAT". Proceedings of the $8^{\text {th }}$ International Conference on Teaching Statistics (ICOTS8).

Latten, S., Martignon, L., Monti, M. \& Multmeier, J. (2011). Die Förderung erster 
Kompetenzen für den Umgang mit Risiken bereits in der Grundschule. Ein Projekt von RIKO-STAT und dem Harding Center. Stochastik in der Schule, (31), 17-25.

Martignon, L. \& Krauss, S. (2009). Hands-On Activities for Fourth Graders: A Tool Box for Decision-Making and Reckoning with Risk. International Electronic Journal of Mathematics Education, 4(3), 227-258.

Martignon, L. \& Kurz-Milcke, E. (2006). Educating Children in Stochastic Modeling: Games with Stochastic Urns and Colored Tinker-Cubes. Hg. v. ICOTS 7 . International Association of Sta-tistical Education (IASE).

Pratt, D., Ainley, J., Kent, P., Levinson, R., Yogui, C., \& Kapadia, R. (2011). Role of Context in Risk-Based Reasoning. Mathematical Thinking and Learning, 13(4), 322-345.

Scholz, R. W. \& Waschescio R. (1986). Kognitive Strategien von Kindern bei Zwei-ScheibenRouletteaufgaben. Beiträge zum Mathematikunterricht.Hannover:

Franzbecker.

Spiegelhalter, D., Pearson, M., \& Short, I. (2011). Visualizing uncertainty about the future. Science, (333), 1393-1400.
Schapira, M. M., Nattinger, A. B., \& McHorney, C. A. (2001). Frequency or Probability? A Qualitative Study of Risk Communication Formats Used in Health Care. Medical Decision Making, (21), 459-467.

Zhu, L. \& Gigerenzer, G. (2004). Children can solve Bayesian problems: the role of representation in mental computation. Key Lab of Mental Health, Institute of Psychology, Chinese Academy of Sciences, Beijing, China; Center for Adaptive Behaviour and Cognition, Max Planck Institute for Human Developement, Berlin, Germany. Retrieved from: http://library.mpibberlin.mpg.de/ft/gg/GG_Child_2006.pdf

$$
\diamond \diamond \diamond
$$

\section{Citation Suggestions :}

APA : Till, C. (2014). Fostering risk literacy in elementary school. Mathematics Education, 9(2), 8396. 